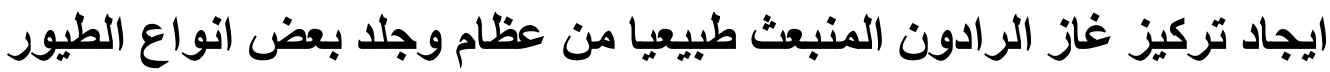

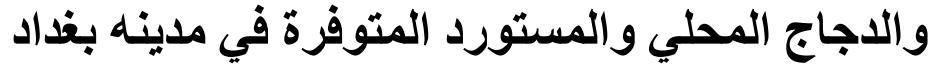

\author{
اثير قاسم مريوش
}

\author{
قسم الفيزياء ، كلية العلوم للبنات ، جامعه بغداد ، بغداد ، العراق \\ استلام البحث 2، تشرين الاول، 2014 \\ قبول النشر 19، تشرين الثناني، 2014
}

(c) (i) (9)

NoDerivatives 4.0 International Licens

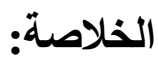

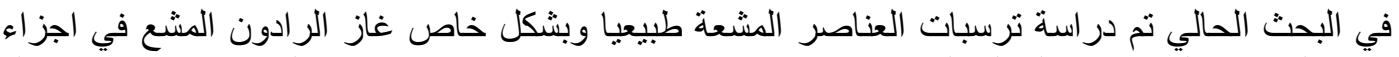

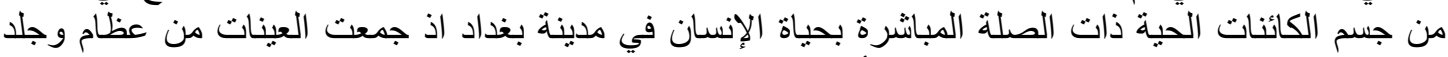

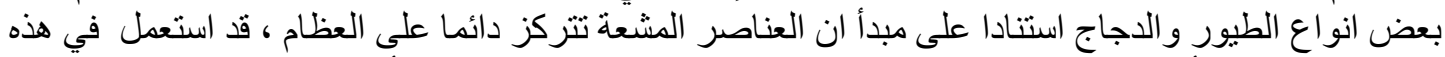

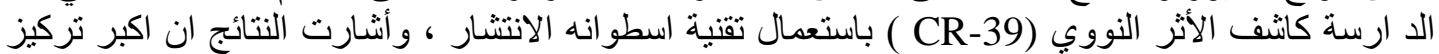

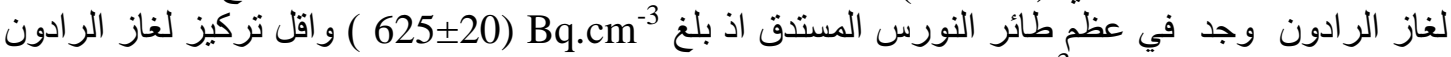

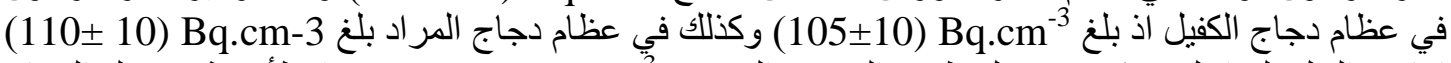

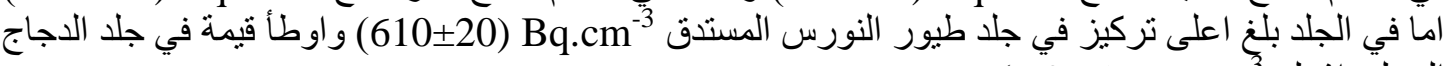

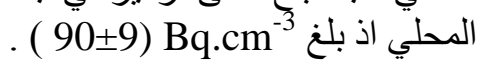

الكلمات المفتاحيه: غاز الر ادون ، عظام وجلد الدجاج و الطيور ، اسطو انه الانتشار ، CR-39.

المساكن والتي تطلق غاز الرادون ( Rn-222 )

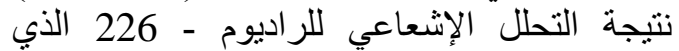

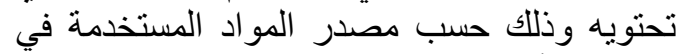

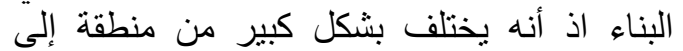

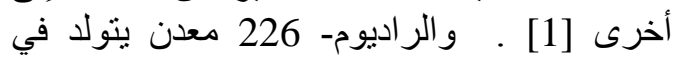

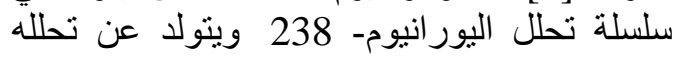

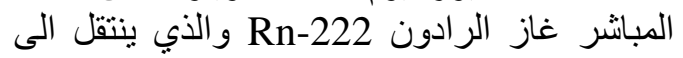

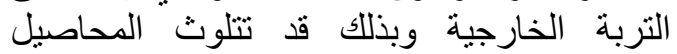

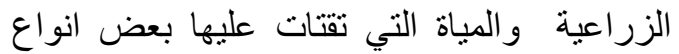

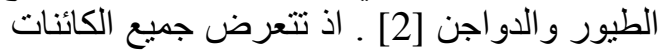

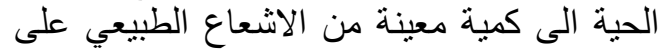

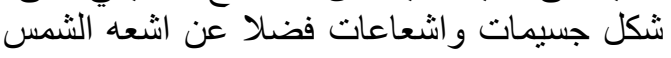

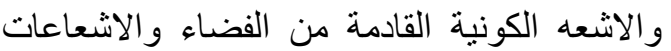
الخلفية الطبيعية وبالاخص النية اليور انبوم الطبيعي الذي الذي الني

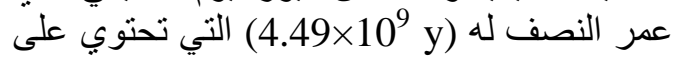
نظير اليورانيوم -238 بنسبة 99.29\% ويور انيوم - 235 بنسبة $0.71 \%$ اذ نتورانيوم نتول هذه العناصر عبر

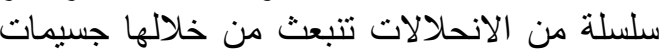

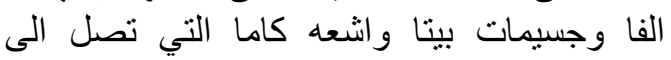

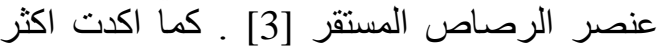

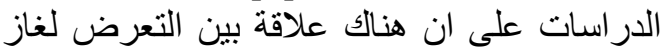

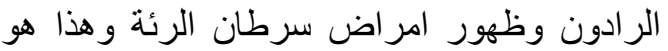

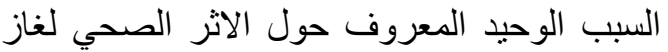
الرادون وفي الحقيقة لبس هو المؤثر ولكن ول لائده

\section{المقدمه :}

ينتمي الر ادون إلى عامود الغاز ات النبيلة أو الخاملة

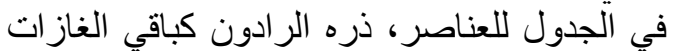

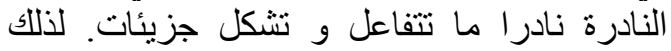

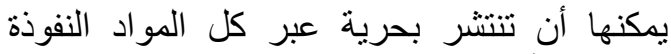

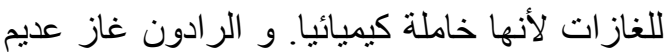

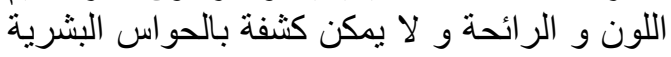

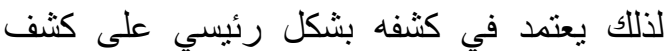

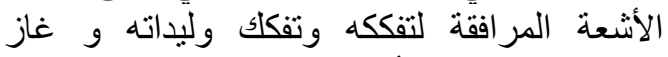

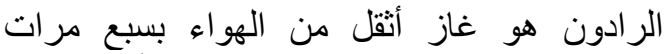
ونصف مما يودي إلى وجوده في الأسفل دائما

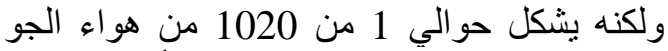
فهو لا يشكل طبقة قريبة من سطح الأرض و و إنما

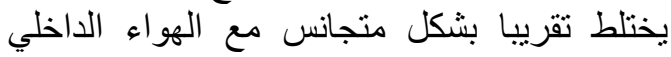
للمنازل حيث يكون تركيز الر ادون داخل المئ المنازل

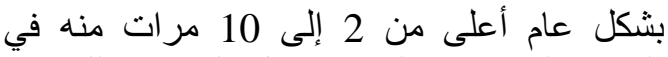

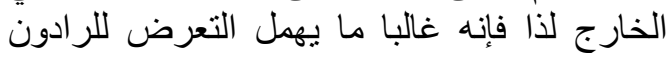

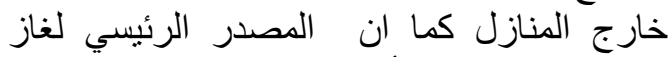

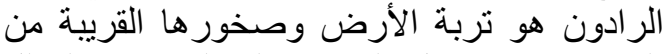

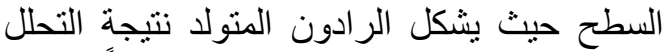

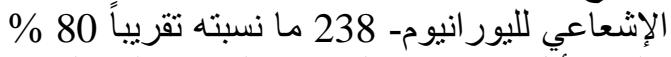

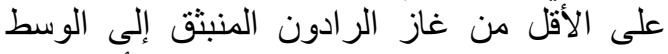

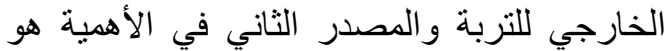

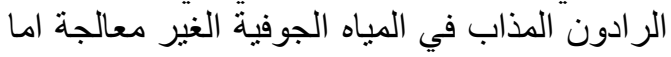

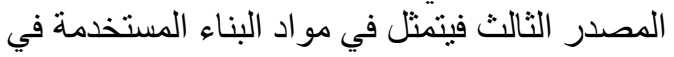


يصبح بعد الكاشف فوق العينات 9 cm ولفترة

90يوما تقريبا كما في الثكل (1).

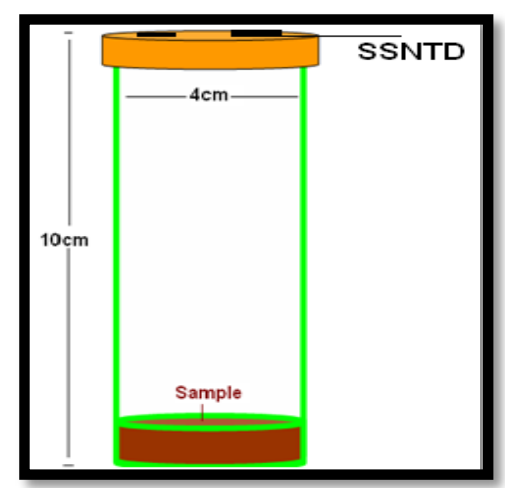

شكل ( 1 ) مخطط لشكل اسطوانة الانتشار

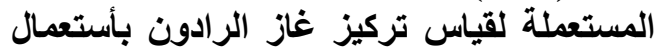
كواشف الاثر النووي CR-39 [5] ـ

بعد الانتهاء من هذه الفترة الزمنية تبدا عملية

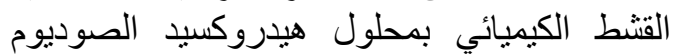
وبعيارية ( NaOH)

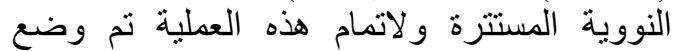

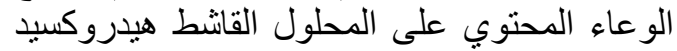

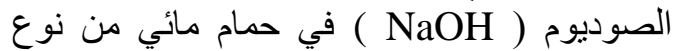

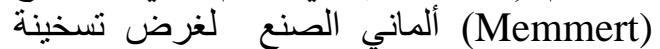

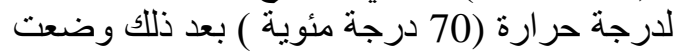

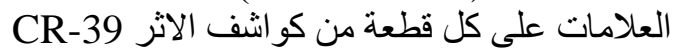

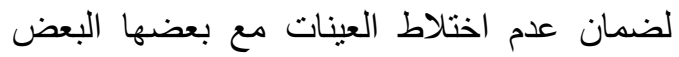

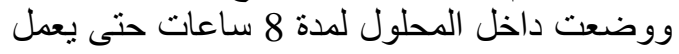

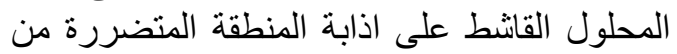

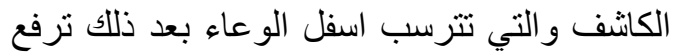
العينات وتغسل بالماء المقطر لعدة مرات الت وتترك جانبا لتجف ، بعد ان جفقت الكو اشف يتم لئم عد الاثار Tracks ياباني الصنع وبقوه تنكبيرية (Olympus) باستعمال عدسة مقسمه الى عدة مربعات (400X)

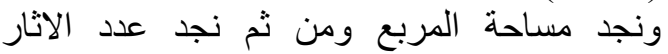
المتكونه داخل المربع لعشر محاولات لات لكل عينة

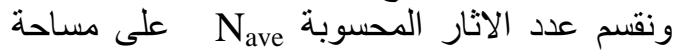

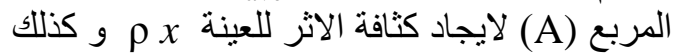
ايجاد ثابت انتشار المنظومة K من العلاقة الاتية

$\mathrm{K}=1 / 4 \times \mathrm{r}(2 \operatorname{Cos} \theta \mathrm{c}-\mathrm{r} / \mathrm{R} \alpha)------(1)$ اذ ان r هي نصف قطر الانبوبة ويساوي 2cm و

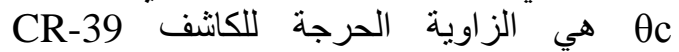

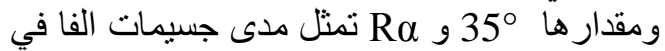

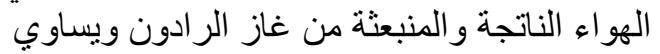
رف 4.15 cm رقم 1 نحصل على قيمة ثابت الانتشار بوحدات المدات الطول وتساوي 0.6 ، اما تركيز غابن الان الراد ادون في
الناتجة من الانحلالات بذات اعمار نصفية قصيره

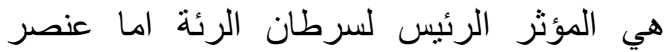

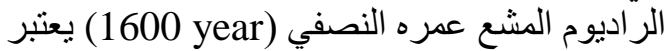
الدصدر الرئيس لمعظم الّئ لائد المشعه طبيعيا

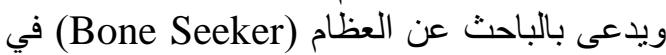
الجسم بسبب التشابه الكبير بين مركباته ومركبات الكبات الكبات الكلور الموجود اصلأ في العظام ولهذا فان مركبئ مركباته

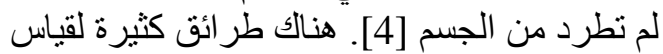

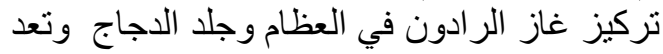
كو اشف الاثر النووي الحالة الصلبة (SSNTDS) واحده من هذه الطرائق اذ اثتبت العديد من الثن

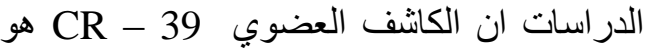
اكثر الكواثف حساسية ويستطيع ان يسجل الآثار الناتجة عن البروتونات حتى تلك التي التي لها طاقة التئة

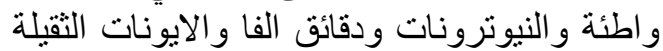

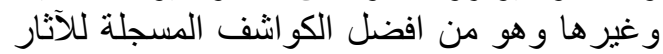

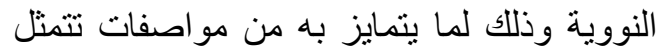

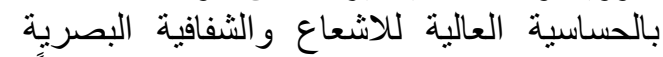

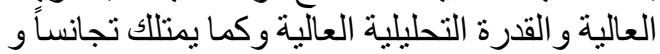

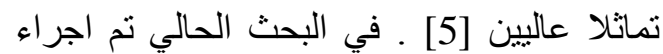

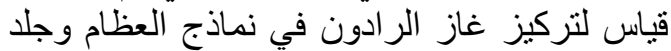

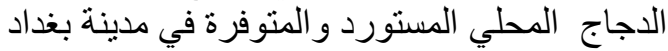
اذ استعملت تقنية اسطو انة الانتشار وكو اشتف الاثن النووي الحالة الصلبة من نوع ( CR - 39 )

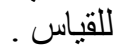

\section{المواد وطر ائق العمل :}

تم جمع 10 عينات من الأسواق المحلية

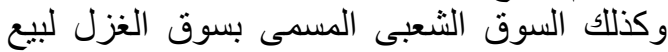

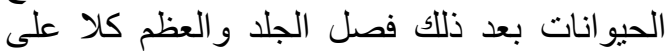

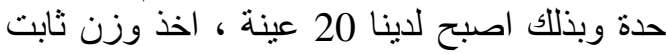

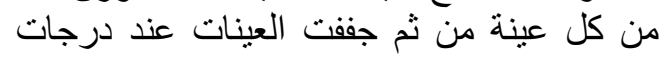
حرارة مرتفعه بالحرق تصل من الى (70C

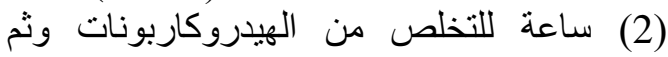
طنتت العينات للحصول على ملى مسحوق اسود

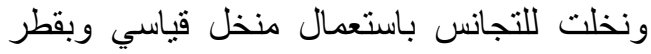

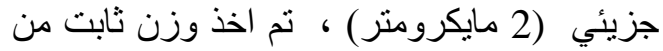

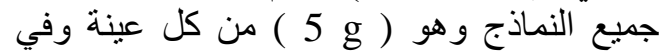
النتيجة تم الحصول على مسحوق اسود مت منجانس يمثل عينة الدارسة ـ تم تحديد التر اكيز الفعالة لغاز للر ادون للعينات المدروسة بوساطة كو اثنف الثيد الآثار النووية للحالة الصلبة (SSNTDS ) اذ استعملت الكينة

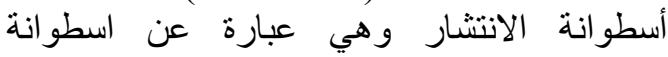

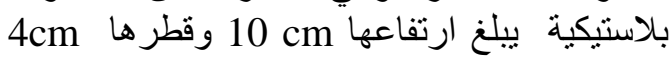

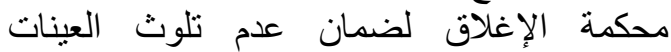
بالمصادر الخارجية اذ نوضع الإنع العينات في أسفل

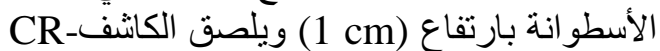
39 في غطاء الاسطو انة من الداخل بمساحة 1.5 وينم غلقها بصورة محكمة بحيث الخاث 
جدول رقم 2 تركيز غاز الرادون في جلا بعض انواع الطيور والدواجن .

\begin{tabular}{|c|c|c|}
\hline 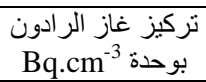 & نوع العينة & رقم العينة \\
\hline $200 \pm 31$ & جلد دجاج ابيض & 1 \\
\hline $100 \pm 9$ & جلد دجاج المر اد & 2 \\
\hline $90 \pm 9$ & جلد دجاج محلي & 3 \\
\hline $100 \pm 9$ & جلا دجاج الكفيلَ & 4 \\
\hline $250 \pm 20$ & جلد دجاج ساديا & 5 \\
\hline $98 \pm 9$ & جلد دجاج كاسكن او غلو & 6 \\
\hline $400 \pm 31$ & جلد طيور الغد & 7 \\
\hline $430 \pm 20$ & جلد طيور حمام ابيض & 8 \\
\hline $610 \pm 20$ & جلد طيور نورس مستدق & 9 \\
\hline $400 \pm 13$ & جلد طائر الزاجل & 10 \\
\hline $258 \pm 10$ & غاز الر ادون في العظام & معدل تر ب ل معل \\
\hline
\end{tabular}

من الجدول في اعلاة نلاحظ ان اعلى تركيز

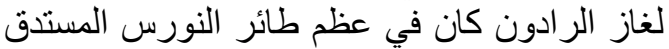

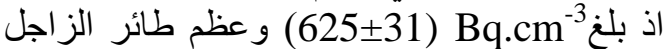
اذ بلغ Bq.cm

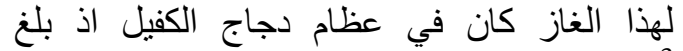
Bq.cm³

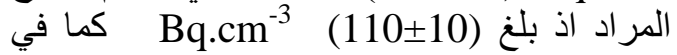
النكل رقم 2.
الحيز المحصورة بين سطح العينة وسطح الكاثنف فيمكن حسابة من المعادلة رقم 2 [7] ل $\rho=\mathrm{K} \times \mathrm{C} \times \mathrm{T}$

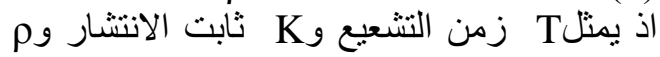
كثافة اثار الجسيمات النووية بوحدة

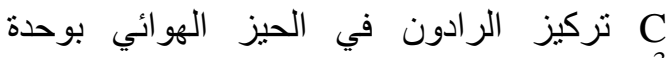
. [6,5] Bq.cm ${ }^{-3}$

\section{النتائج والمناقشة :}

في البحث الحالي تم ايجاد نراكيز غاز

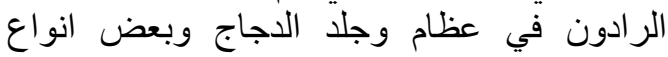

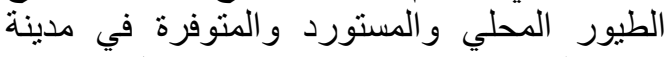

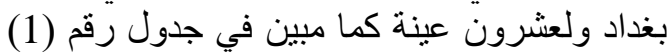

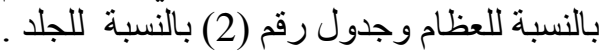

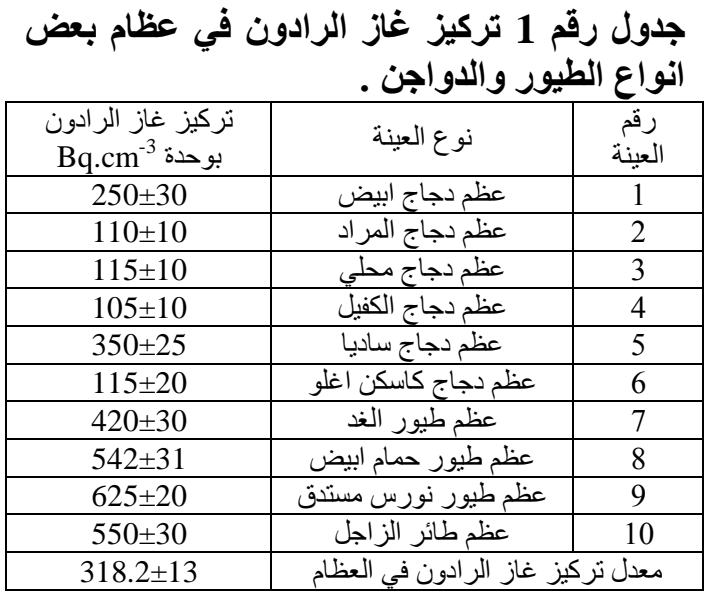

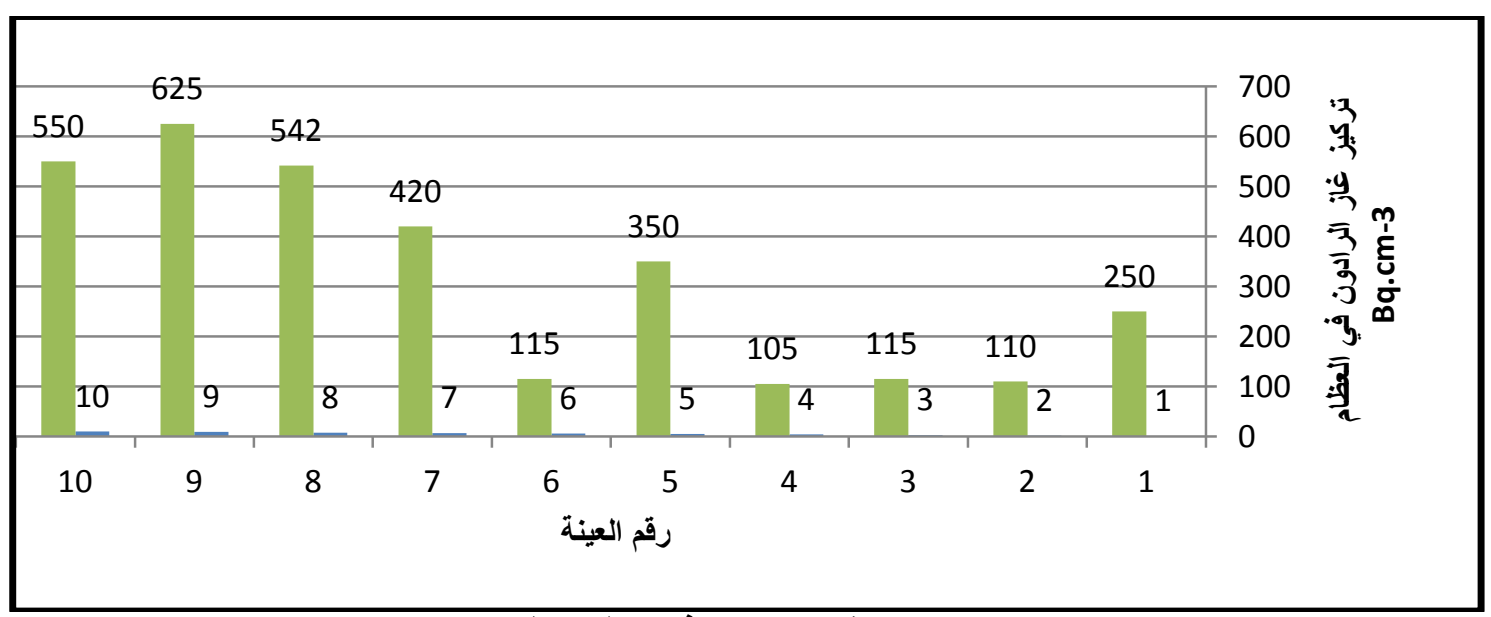

شكل (2 ) يوضح تركيز غاز الرادون في عظام الطيور والدواجن .

وجلد دجاج كاسكن اوغلو تركي المنشا اذ بلغ روكما هو موضح في الثكل رقم 3.
اما بالنسبة لتر اكيز غاز الر ادون في الجلد قد كانت

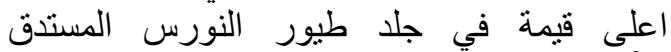
جا جلد الدجاج المحلي اذبلغ Bq.cm 


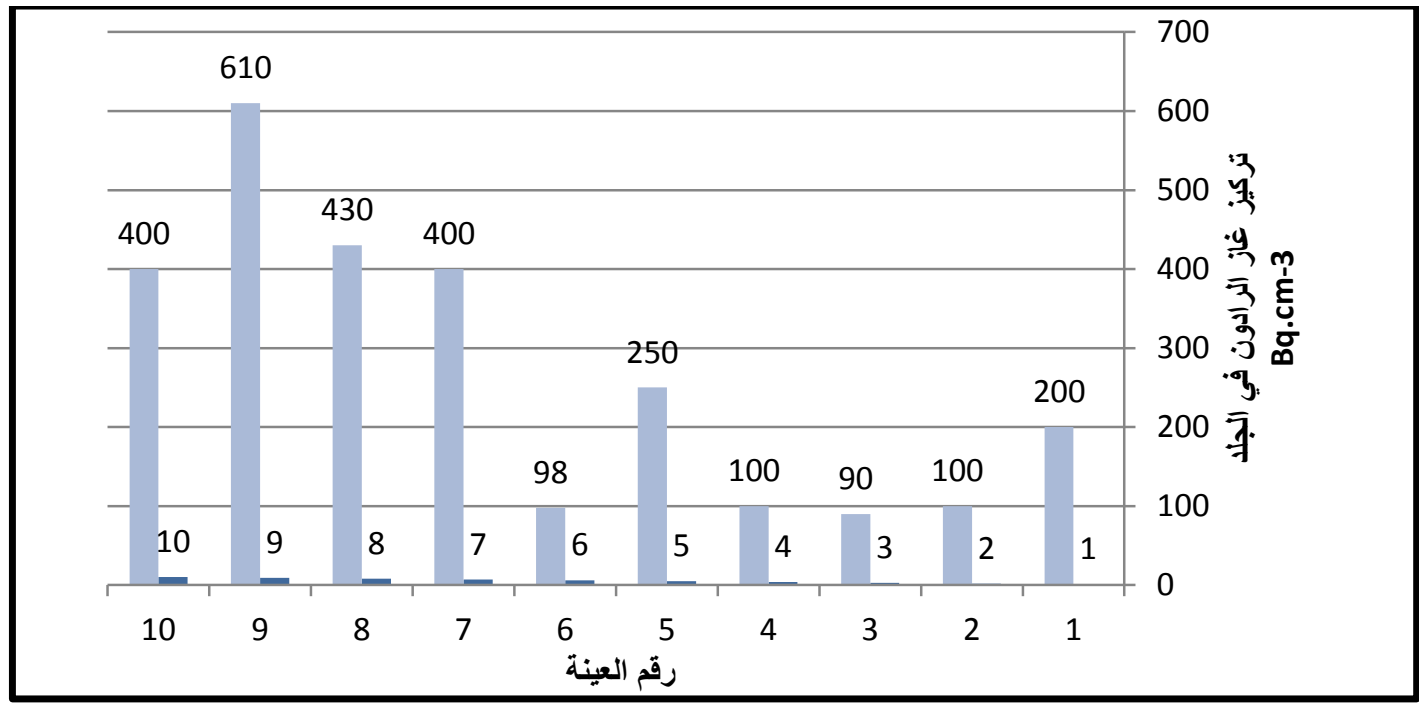

شكل (3 ) يوضح تركيز غاز الرادون في جلد الطيور والدواجن .

النتيجة يمكن اعتبار ها طبيعية لانه من المعروف هناك زيادة في تركيز غاز الرنائ طادون في المياه

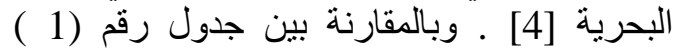

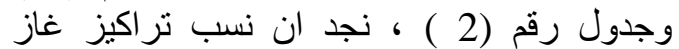
الر ادون في العظام على العموم اكبر من التر اكيز

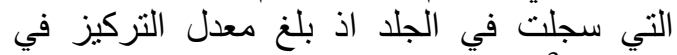

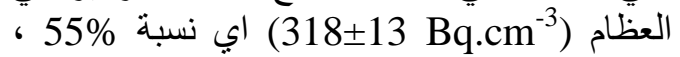

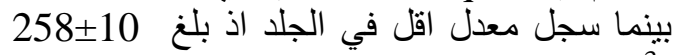
(Bq.cm²)

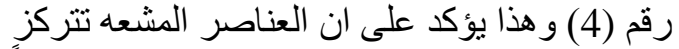
في العظام ،هذا وكما اكدته الدر اسـات السابقة ايضاً

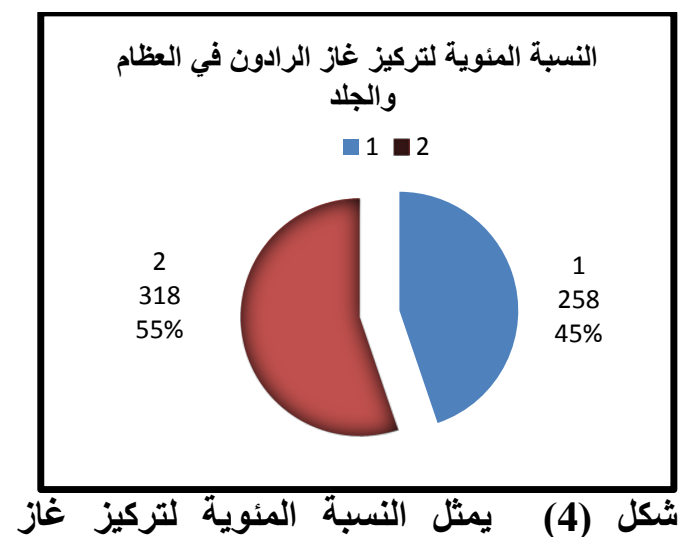

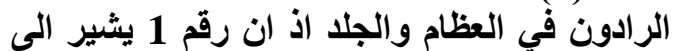
النسبة المئوية لتركيز الرادون في الجلا ورئ ورقي 2

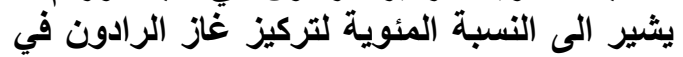
العظام - العبر

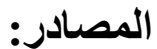

[1] شروق جاسم جبار ـ 2011. ايجاد تراكيز اليور انيوم و الرادون وبعض العناصر الثقيلة
ولا يوجد مقياس يمكن الاستناد علية لمعرفة مدى الأى الئي خطورة هذه النسب على صحة الانسان إذ ليس للإن

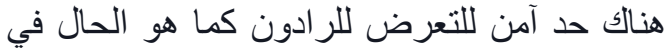

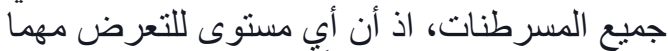

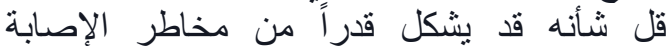

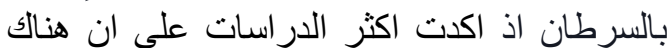

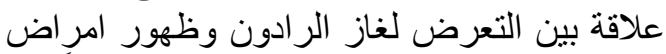

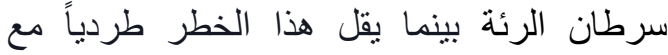

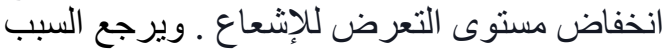

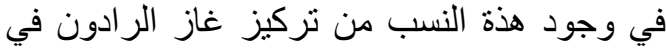

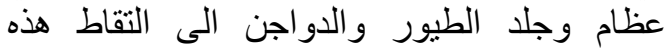

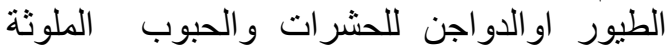

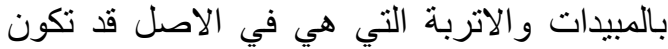

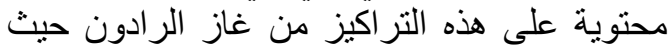

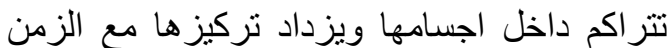
فاذا تناولها الانسان كانت سما بطيئا كلما تراكم لرئ

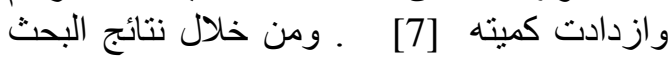

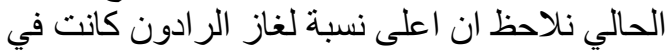

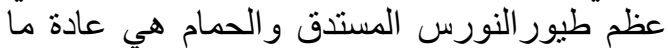

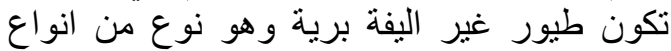

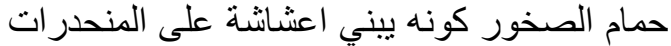

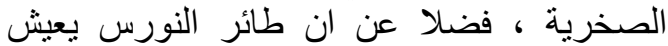
قرب السواحل و الجزر و المدن المطلة الدئة على البحار

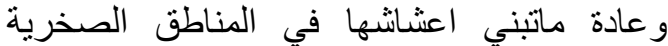
و المنحدرات التي تعتبر هذا النئي النوع من المناطن المناطق بالمناطق الصخرية و الكهوف مصدر الترا من مصنادر التراط الترق غاز الرادون اذ إن حوالي

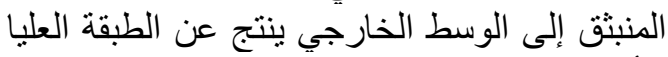

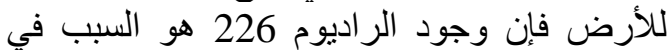
إصدار الر ادون في التربة وبالتالي تختلف التر من مكان

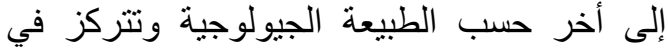

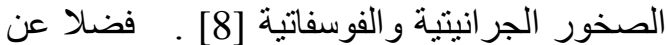
انها تتغذى على الاسمالك الصغيرة البحريه وهذه 
الخشب المستورد والمحلي باستعمال كاثف

الاثر النووي للحالة الصلبة ، مجلة بغداد

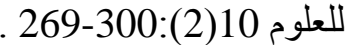

[6] Azam A. Naqvi A. H. and Srivastava D. S. 1995. Radium Concentration and Radon Exhalation Measurements Using LR - 115 Type II Plastic Track Detectors , Nucl. Geophys., 9(6): $653-657$.

[7] وحدة ابحاث الثلوث الاشعاعي والبيئي . 30 ابريل 2013.

[8] دورة تدريبية في هيئة الطاقة الذرية ـ 2000 ـ

طرق و اساليب القياسات الاشعاعية ـ مجلة

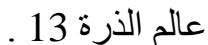

في تربة مدينة الكوت، رسالة ماجستير ـ كلية العلوم للبنات .

[2] Yakovleva V. S. 2003. safe from the effects of radiation, Proceeding of ICGG 7: $28-30$.

[3] نشأة رحيم ،حليمة جابر ،باسم حسن . 2008 ـ

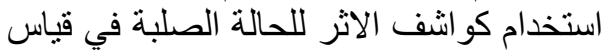

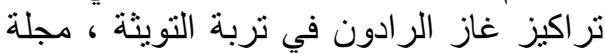

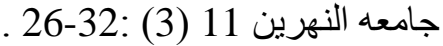

[4] سارة عبد الامير ، عبد الرضا حسين ـ 2013.

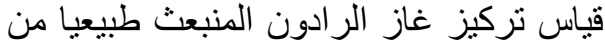

نماذج الكائنات الحية المتوفرة في في محافظة الرنة

البصرة ، مجلة ابحاث البصرة 39 الجزء

. B.4

[5] دوسر حسين ، باسم خلف ،زينب حازم .

2013. قياس تركيز غاز الرادون المشع في بـ في

\title{
Find the concentration of radon gas emitted naturally from the bones and skin of some kinds of birds and local and imported chicken available in the City of Baghdad
}

\author{
Atheer Qassim Mryoush \\ Department of Physics, College of Science for Women, University of Baghdad. \\ Received 2, October, 2014 \\ Accepted 19, November, 2014
}

\begin{abstract}
:
In the present research we the study the deposition of radioactive elements naturally and particularly radioactive radon gas in parts of the body of organisms which are of direct relevance to human life in the city of Baghdad as the samples which were collected from the bones and skin of some kinds of birds and chicken based on the principle that radioactive elements are concentrated always on the bones. We use of this as the exercise detector impact nuclear (CR-39), using the technology Cylindrical diffusion, the results indicated that the largest concentration of radon found in the bone bird Seagull tapered as it was $(625 \pm 37) \mathrm{Bq} \cdot \mathrm{cm}^{-3}$, and less concentration of radon gas in the chicken bones of Al-kafeel as it was $(105 \pm 10)$ Bq. $\mathrm{cm}^{-3}$ as well as in chicken bones of Al-muriad to be reached $(110 \pm 10) \mathrm{Bq} \cdot \mathrm{cm}^{-3}$ either in the skin reached the highest concentration in the skin of seagulls tapered(610 $\pm 20) \mathrm{Bq} \cdot \mathrm{cm}^{-3}$ and the lowest value in the skin local chicken as it was $(90 \pm 9) \mathrm{Bq} . \mathrm{cm}^{-}$
\end{abstract}

Key words: Radon Gas, Bones and Skin of Birds and Chicken, Cylindrical diffusion, CR-39. 